\title{
GÁS NATURAL - PARTICIPAÇÃO PRIVADA - CONCESSÃO DE OBRA PÚBLICA
}

\section{PARECER}

\section{I \\ CONSULTA}

Mediante acordo binacional, de que participam o Brasil e a Bolívia, ajustou-se a importação de gás natural, de origem boliviana, com a consequiente construção de gasoduto para $o$ transporte de matéria-prima de modo a atender à sua entrega ao consumo em território nacional.

Cogita-se da possibilidade de participação da iniciativa privada no tocante à atividade de transporte do produto, a qual, por sua natureza, está inserida no monopólio em favor da União.

Para o exame da matéria -- que constitui objeto da consulta - impõe-se apreciar, como premissas necessárias, o sistema constitucional da ordem econômica, a legislação pertinente ao monopólio estatal e a admissibilidade de colaboração privada no exercício da atividade monopolizada.

\section{II \\ A ORDEM ECONÔMICA NA CONSTITUIÇÃO DE 1988}

O texto constitucional vigente consagra o princípio geral do livre desempenho de qual qualquer atividade econômica e prestigia, em mais de um passo a livre iniciativa e a livre concorrência. Este é o sentido do parágrafo único do artigo 170 e das disposições do artigo $1^{\circ}, n^{\circ} I V$, do artigo 170 , em seu caput e no item IV deste preceito, apenas admitida a presença direta do Estado, quando necessária ao atendimento de imperativos de segurança nacional ou a relevante interesse coletivo, conforme definição em lei (art. 173).

Contudo, ao Estado é atribuída a qualidade de agente normativo e regulador da atividade econômica, cumprindo à lei estabelecer as di- retrizes e bases do desenvolvimento nacional (art. 177, $\S 1^{\circ}$ ). Apenas indicativo para o setor privado, o planejamento afeto ao Poder Público, condiciona a liberdade econômica, submetida ao postulado da justiça social, que a legítima (José Afonso da Silva - Curso de Direito Constitucional Positivo - $8^{\mathrm{a}}$ edição 1992 - p. 673).

O Estado será partícipe direto da atividade econômica quando, nos termos de lei autorizativa, venha a exercê-la por meio de empresa pública ou sociedade de economia mista, sujeitas em sua funcionalidade, ao regime próprio das empresas privadas (art. $173, \S 1^{\circ}$ ) e, portanto, colocadas no plano da concorrência.

Destaca, porém, a Constituição atividades específicas, sobre as quais opera o monopólio da União, com a interdição de acesso à iniciativa privada (art. 177).

A convivência dos regimes de liberdade econômica e intervenção estatal reflete a tendência marcante nas modernas Constituições decorrentes antagônicas no propósito de alcançar o termo médio de harmonia entre os rumos díspares na condução da economia.

A linha dominante no direito público a partir da década de 30 , atribui ênfase, no conceito de democracia, à proteção do interesse coletivo contra os excessos absorventes do capitalismo. A definição de VIGORITA exprime essa tendência: "lo Stato di diritto si veste dell'attributo di sociale" (L' iniciativa economica private nel diritto pubblico - $1959-\mathrm{p}$. 39).

Entre nós, ao liberalismo puro da primeira Constituição republicana sucede-se, a partir da Carta Magna de 1934, a limitação da livre economia segundo os princípios da justiça e as necessidades da vida nacional (art. 115).

A intervenção no domínio econômico, como medida excepcional de resguardo do bem público, acolhida no art. $175 \mathrm{da}$ Constituição de 1937, consigura-se como instrumen- 
to de justiça social, conciliando a liberdade de iniciativa com a valorização do trabalho humano, conforme o art. 145 da Constituição de 1946 e, a par da função social de propriedade, consagra-se como princípio da ordem econômica no regime constitucional de 1967/69 (art. 157 do texto original e art. 160 da Emenda Constitucional $\mathrm{n}^{\circ}$ l).

MANOEL GONÇALVES FERREIRA FILHO destaca o "caráter comfosto" da Constituição de 1988 (Curso de Direito Constitucional - Saraiva - $17^{\mathbf{a}}$ edição, p. 72) e MIGUEL REALE registra que a Carta Magna em vigor "optou por uma posição intermédia entre o liberalismo oitocentista, infenso a toda e qualquer intervenção do Estado e o dirigismo estatal. Dir-se-ia que sua posição corresponde à do neoliberalismo ou social-liberalismo, o único, a nosso ver, compatível com os problemas existenciais de nosso tempo" (Aplicações da Constituição de 1988 — Forense 1990 - p. 13). RAUL MACHADO HORTA observa que "a Ordem Econômica na Constituição de 1988 está impregnada de princípios e soluçōes contraditórias. Ora inflete no rumo do capitalismo neoliberal, consagrando os valores fundamentais desse sistema, ora avança no sentido do intervencionismo sistemático e do dirigismo planificador, com elementos socializadores" (A Constituição Brasileira de 1988 - Interpretações - obra coletiva do II Forum Jurídico - Forense Universitária 1988 - p. 392).

A vigente Constituição inclina-se, em suma, para paralelismo de princípios que se devem coordenar em exegese construtiva, integrando a livre iniciativa com a valorização do trabalho, as noções do planejamento estatal e da liberdade de mercado, visando ao equilíbrio harmônico entre a liberdade da empresa e a regulamentação da atividade econômica.

À luz dessa ambivalência devem ser entendidas e interpretadas as linhas mestras da ordem econômica na Vigente Constituição.

\section{III}

\section{CONCORRÊNCIA E MONOPÓLIO NA ECONOMIA}

A livre concorrência é a matriz do sistema capitalista. A Constituição de 1988 a recebe entre os principios fundamentais da ordem econômica (art. 170, $\mathrm{n}^{\circ}$ IV).

É, porém, o uso - jamais o abuso - a tônica de normalidade do livre jogo das forças da economia privada.

Na medida em que a livre iniciativa tende à dominação dos mercados ou à eliminação da concorrência a lei repelirá, até mesmo no plano penal, os abusos do poder econômico conforme o comando constitucional vigente (art. $173, \S 4^{\circ}$ ) em continuidade do direito anterior.

No plano conceitual impõe-se distinguir o monopólio de fato e o monopólio de direito, perante os quais diversamente se comporta a ordem jurídica.

No monopólio de fato a concentração capitalista se exacerba materialmente em detrimento da liberdade econômica, e a norma jurídica secundária opera como sanção à conduta ilícita, em defesa do princípio da concorrência.

Quando, no entanto, o interesse público recomenda que se reserve ao Estado a exclusividade de determinada atividade econômica de proteção de irrelevante interesse geral, a norma jurídica se dirige, primariamente, à garantia do privilégio estatal.

É mister caracterizar um monopólio de fato em confronto com um monopólio jurídico. $\mathrm{Na}$ primeira modalidade, o monopolizador adquire a qualidade por ato próprio, fundada em condições peculiares de poder econômico ou de tecnologia privilegiada, tendentes a excluir a concorrência de terceiros.

Contrariamente, no monopólio de direito, é a lei que torna privativa do Estado a atividade econômica, emitindo ato de vedação da concorrência, declarada ilícita.

RENATO ALESSI destaca, com nitidez, o conteúdo das situações de direito:

"nel campo economico è la posizione del monopolista ed i suoi effette, che vengono in considerazione eche pertanto devono essere studiati; invece nel campo giuridico è il vinculo imposto ai terzi che viene in considerazione come oggetto dell' indagine."

No plano jurídico - adverte o autor quanto à última categoria - “i monopólio si sotanzia in un divieto posto ai terzi di produrre o di vendere qual bene o qual servizio". 
(Novissímo Disgesto Italiano - vol. X verbete Monopoli di Stato - p. 866).

BERLIRI abona a mesma discriminação. Invoca a lição de RAGGI para definir o monopólio de fato e o monopólio de direito.

Aquele, - o monopólio de fato - , fruto de razões naturais de produção, importa em que um só país ou uma só pessoa, ou uma coalizão de pessoas, inviabilize a outrem a atividade concorrencial:

"monopólio di diritto, invece, è il privilegio assicurato e creato da una norma di legge, in forza delle quale, una determinata pesona od ente puo produrre o vendere determinante oggetti o rendere al pubblico determinati servizi ad escluzione di ogni altro individuo."

(ANTONIO PERLIRI - Principi di Diritto Tributario - volume I - 1952 - p. 361).

A posição do legislador é diversa nas duas formas de monopólio.

Perante o monopólio de fato, que se torne ofensivo ao direito ou liberdade, a norma legal protege terceiros contra os excessos do agente monopolizador, ofensivas à ordem jurídica.

No monopólio de direito, a lei se endereça a terceiros, vedando-lhes a invasão da atividade privativa do titular do monopólio.

No primeiro caso, a ilicitude conter-se-á na ação abusiva do monopolizador privado. $\mathrm{Na}$ segunda hipótese, em defesa do monopólio público, a ilicitude se apresenta quando violada por terceiros a reserva da atividade estatal monopolizada.

\section{IV \\ MONOPÓLIO DO GÁS NATURAL}

as Constituições anteriores admitiam a possibilidade de que a lei federal viesse a declarar o monopólio estatal de determinada indústria ou atividade econômica sem qualificá-las (Constituição de 1934, art. 116; Constituição de 1940, art. 146; Constituição de 1967, art. 157, $\$ 8^{\circ}$; Emenda Constitucional $\mathrm{n}^{\circ} 1$, de 1969, art. 163).

Foi além a Constituição de 1988. Consignou, de forma direta, modalidades especificas de monopólio da economia, em favor da
União (art. 177) ou do Estado-membro (art. $25, \S 2^{\circ}$ ).

À indeterminação anterior quanto à espécie de monopólio, o constituinte de 1988 preferiu a enumeração taxativa, de tal forma que novos tipos de monopólio estatal somente são possíveis por emenda constitucional (DIOGO DE FIGUEIREDO MOREIRA NETO - Ordem Econômica e Desenvolvimento na Constituição de 1988-1989 - p. 74).

No que interessa à matéria da consulta, constitui monopólio da União a importação e o transporte de gás natural de qualquer origem (art. 177, $\mathrm{n}^{\circ}$ III e IV).

Defere-se ao legislador ordinário regular a forma e a extensão do monopólio assim estabelecido a importar na interdição de iniciativa de outra fonte na exploração da atividade monopolizada. Nem ao particular, nem aos Estado, é facultada a extração, importação, exportação ou transporte do gás natural.

\section{$\mathrm{V}$ \\ A RECEPÇÃO DO DIREITO ORDINÁRIO ANTERIOR À CONSTITUIÇÃO}

No Estado de Direito a força obrigatória das leis emanas da competência atribuída, na Constituição, aos poderes constituídos para emitir atos normativos.

Revogada uma Constituição interrompe-se o nexo de legalidade que serve não de alicerce à validade e eficácia das leis.

Contudo, como uma nova Constituição surge em sucessão à que se extingue, opera-se de imediato, como uma Fénix mitológica, a instantânea repristinação do direito anterior, restaurado pela Constituição superveniente, na medida em que com ela se harmonize.

A este fenômeno de continuidade do direito legislado corresponde a teoria da recepção da ordem jurídica na sucessividade das Constituições.

O conjunto de normas jurídicas anteriores diz-se recebido pela Constituição nova uma vez comprovada a compatibilidade de conteúdo. 
Revoga-se a lei incompatível e se prolonga, independentemente de ato declaratório, a norma jurídica que ratione materiae poderia ser emitida em face da nova disciplina constitucional.

A lei (como regulamento outro ato normativo secundário) no mesmo momento se exaure e renasce, quando sua existência e validade passam a conviver com o novo universo constitucional.

A lição excelente de JORGE MIRANDA descreve o processo da continuidade do direito ordinário anterior a uma nova Constituição:

"o que a superveniência de uma Constituição provoca é novação do Direito ordinário anterior. Como todas e cada uma das normas legislativas, regulamentares e outras, retiram a sua validade, direta ou indiretamente, da Constituição, a mudança da Constituição acarreta mudança de fundamento de validade: as normas, ainda que formalmente intocadas, são novadas, no seu título ou na sua força jurídica, pela Constituição; sistematicamente deixem de ser as mesmas.

Há assim, uma nítida diferença entre a situação do Direito Constitucional anterior - o qual cessa com a entrada em vigor da nova Constituição - e a do Direito ordinário anterior - o qual continua com novo fundamento de validade e sujeito aos princípios materiais da nova Constituição e que somente em caso de contradição deixará de vigorar."

(JORGE MIRANDA - Manual de Direito Constitucional $-2^{\mathrm{a}}$ edição - Tomo II $-\mathrm{p}$. 242/243).

A concepção remonta ao ensinamento de Kelsen:

"Si siertas leyes promulgadas bajo el imperio de la vieja Constitución "continuan siendo válidas" bajo Constitución nueva, ello únicamente es posible porque la nueva Constitución les confiere validez, ya expressa, ya tácitamente. El fenómeno es un caso de recepción (semejante a la del Derecho Romano). El nuevo orden "recibe", es decir, adopta normas del viejo orden; estro significa que el nuevo considera válidas (o pone em vigor) normas que poseen el mismo contenido que las del precedente. La "recepción" es um procedimento abreviado de creación jurídica. Las leyes que, de acuerdo com la manera ordinaria e inadecuada de hablar, continúan siendo válidas, son, desde um punto de vista jurídico, leyes nuevas cuyo sentido coincide com el de las anteriores."

(HANS KELSEN - Teoria General del Derecho y del Estado - tradução mexicana - 1969 - p. 138).

A tese da recepção do direito anterior a uma nova Constituição tem trânsito livre na jurisprudência do Supremo Tribunal Federal (RTJ-71/289 e 77/687) e na doutrina nacional (ver, entre outros, MANOEL GONÇALVES FERREIRA FILHO - O Poder Constituinte - $2^{\circ}$ edição - 1985 - p. 88/9; SAULO RAMOS - Consultoria Geral da República Poder SR-71/88 - Diário Oficial da União 11-10-88 - p. 19804/s; Parecer n ${ }^{\circ}$ SR-72/88 - Diário Oficial da União de 18-10-88 p. 20263/s; Despacho in RDA-174/208-209).

Tivemos ensejo de ponderar, em parecer publicado na Revista de Direito Público - vol. 99/57 que

"Promulgada uma nova Constituição, não desaparece necessariamente o ordenamento anterior que a antecede.

As leis vigentes, desde que compatíveis com o novo diploma constitucional, não são por ele revogadas e perduram válidas e eficazes.

O direito anterior não contraditado é recebido pelo novo sistema constitucional que passa a imprimir-lhe o selo de constitucionalidade, sem hiato ou interrupção.

A teoria da recepção, fundada no princípio da continuidade do ordenamento, prolonga a vigência e eficácia das leis ordinárias ou complementares que não forem materialmente contrarias ao novo Estatuto Político."

Recebida pela nova Constituição, a lei anterior não sofre solução de continuidade e a sua obrigatoriedade perdura no tempo segundo as regras comuns de vigência.

\section{VI \\ A RECEPÇÃO DA LEI N 2004/53}

Na vigência da Constituição de 1946, com a promulgação da Lei n 2004 , de 3 de outubro 
de 1933, criou-se o monopólio da União sobre a pesquisa, lavra e transporte de petróleo e gases raros (art. $1^{\circ}$ ), a ser exercido pelo Conselho Nacional de Petróleo, como órgão de orientação e fiscalização e, como órgão de execução, por meio da sociedade por ações Petróleo Brasileiro S.A. (PETROBRÁS) e suas subsidiárias, a serem constituídas na forma prevista na mesma lei (arts. $2^{\circ}$ e $5^{\circ}$ ).

À União é assegurado o controle da sociedade, pela maioria do capital votante, admiti$\mathrm{da}$, em proporção fixada na lei, a participação de pessoas físicas brasileiros natos ou naturalizados e de pessoas jurídicas de direito privado (art. 18).

A extensão de abrangência, no monopólio por esta forma, regulado, em favor da Petrobrás, ficou definida, por interpretação autêntica do próprio legislador no texto da Lei $n^{\circ}$ $2.004 / 53$, quando transfere, a título de integralização do capital, os bens e direitos relacionados com gases naturais (art. 10).

$E$, adiante, reafirma-se a incorporação ao capital da PETROBRÁS de direitos sobre jazidas de gases naturais que existiam ou viessem a existir em território dos Estados e Municípios (art. 10, $\S 3^{\circ}$ ).

Consequuentemente, desde então, o monopólio estatal compreendia não somente a exploração do petróleo e seus derivados, como também a dois gases naturais, inseridos no patrimônio da empresa pública.

Previsto na Constituição de 1988 o monopólio da União relativamente à importação e transporte do gás natural (art. 177, $\mathrm{n}^{\circ}$ III e IV), a citada Lei $n^{\circ} 2004 / 53$ - editada com fundamento em Constituição anterior - foi recebida e convalidada pelo princípio de compatibilidade perante a Carta Magna advinda.

A criação da PETROBRAS mediante lei específica preenche o requisito formal do art. 37, a. XIX da vigente Constituição e, de igual modo, a expressa admissão de subsidiárias, satisfaz à exigência de autorização legislativa prévia e específica (art. $37 \mathrm{n}^{\circ} \mathrm{XX}$ ).

$\mathrm{A}$ identidade de fundamento constitucional quanto à instituição do monopólio da União assegura, em (uma, a continuidade da Lei $n^{\circ}$ 2004/33, na regência da execução do monopólio federal no setor.
Ademais, para exercê-lo, é lícito a criação de subsidiária da PETROBRÁS, como autorizado na lei que a institui, permitida a participação minoritária de pessoas jurídicas de direito privado, na mesma proporção autorizada para a empresa matriz (art. 39 da Lei $n^{\circ}$ 2004/53).

A subsidiária, constituída como sociedade de economia mista, obedecerá ao regime próprio das empresas privadas (art. $173, \S 1^{\circ}$ da Constituição) com a ressalva dàs peculiaridades inerentes ao exercido da atividade estatal monopolizada.

A latitude de sua atuação será compatível com o objeto e finalidade da PETROBRÁs, observada, em sua constituição, o disposto no art. $235, \S 2^{\circ}$ da Lei de Sociedades por Ações (Lei $n^{\circ}$ 6.404, de 15 de dezembro de 1976), extensível ao regime do acionista controlador.

A criação de subsidiária com prévia aprovação do Departamento Nacional de Combustíveis (sucessor do Conselho Nacional de Petróleo - Decreto $n^{\circ}$ 99.244, de 10-5-92) e, no uso da autorização legislativa - como visto recebida pela nova Constituição - far-se-á mediante deliberação societária, em Assembléia Geral Extraordinária.

A participação do capital privado na subsidiária terá de afeiçoar-se à natureza e proporcionalidade ditadas para a empresa principal.

A ser entendida necessária ou conveniente outra proporção, somente mediante lei nova, poderá ser alcançado o resultado.

Em qualquer hipótese, a forma de participação do acionista ou acionistas minoritários merecerá ser definida em acordo de acionistas, regulando diretrizes e obrigações.

\section{VII \\ OUTRAS FORMAS DE PARTICIPAÇĀO DA INICIATIVA PRIVADA}

A par da qualidade de acionista minoritário em subsidiária a ser constituída, a iniciativa privada poderá ser chamada a colaborar na gestão de atividade monopolizada a título de prestador de serviço, mediante prévia licitação, nos termos da lei própria. 
O chamado regime de terceirização é compatível com a execução de serviços públicos, inclusive dos monopolizados.

Tanto a construção do gaseoduto, como outras modalidades de serviços de assistência técnica ou execução de obras, poderão ser adjudicadas a empresas privadas.

Mais ainda, a nosso ver, poderá ser estendida a tais contratos, mediante lei especial, o regime de financiamento aplicado às concessões de obras públicas, amplamente adotadas, no passado, para a construção de portos e, mais recentemente, autorizadas para rodovias federais, conforme o Decreto $n^{\circ} 94.002$, de 4 de fevereiro de 1987.

Nesta hipótese, incorporando-se os respectivos bens ao patrimônio da sociedade de economia mista, será delegada a gestão, por período determinado, de modo a permitir, com a fruição da receita operacional, a amortização e remuneração do capital investido.

\section{VIII CONCLUSÕES}

Do exposto, é válido concluir-se que:

$1^{\circ}$ - o monopólio de exploração do gás natural outorgado à União nos termos do artigo 177 da Constituição de 1988 deve ser executado em conformidade com a Lei $n^{\circ} 2004 / 53$, recebida pela atual Constituição, por ser com ela compatível;

$2^{\circ}$ - a criação de subsidiária da PETROBRÁS, conforme faculta a referida lei, tornará possível a participação de capital privado, com observância da proporção fixada para esse fim, na mesma lei; $3^{\circ}$ - criação de subsidiária far-se-á nos termos da lei das sociedades comerciais, facultando-se, no estatuto ou em acordo de acionistas, a regulação dos direitos do minoritário privado;

$4^{\circ}$ - eventual alteração da proporcionalidade ou forma diversa de participação deverá ser objeto de lei especial, que modifique o esquema estabelecido no regime legal em vigor, desde que, seja respeitado, o privilégio da União, como acionista controlador;

$5^{\circ}$ - sem prejuízo do respeito ao princípio do monopólio, será válida, mediante prévia licitação, a contratação de empresa privada para a prestação de assistência técnica ou a execução de obra ou serviço vinculado à atividade monopolizada.

$6^{\circ}$ - mediante lei especial caberá adotar-se modalidade análoga à da concessão de obra pública, como processo de financiamento de serviço. Mediante licitação poderá ser celebrado contrato de construção de instalações, garantindo-se a retribuição e remuneração do contratado mediante percepção a tempo certo, da receita produzida. As instalações serão incorporadas ao serviço, assegurando-se a gestão à empresa contratada pelo prazo convencionado.

Entre os requisitos de habilitação da empresa a ser contratada devem figurar, como paradigma, os que, por lei, são exigidos dos acionistas minoritários, em respeito ao princípio de nacionalização da atividade.

São estas as ponderações que me ocorre fazer sobre a matéria, que por sua originalidade desafia a criatividade do intérprete.

Assim nos parece, SMJ. Rio de Janeiro, 26 de abril de 1993. Caio Tácito. 